\title{
Cutter Head Approximation Machining Method of Line Contact Spiral Bevel Gear Pairs Based On Controlling Topological Deviations
}

\author{
Mingyang Wang \\ Tianjin University \\ Yuehai Sun ( $\square$ yuehaisun@tju.edu.cn ) \\ Tianjin University
}

\section{Research Article}

Keywords: Spiral bevel gear, line contact, NC machining method, tooth flank mathematical model, contact simulation

Posted Date: December 28th, 2021

DOl: https://doi.org/10.21203/rs.3.rs-1154716/v1

License: (c) (i) This work is licensed under a Creative Commons Attribution 4.0 International License.

Read Full License 


\title{
Cutter head approximation machining method of line contact spiral bevel gear pairs based on controlling topological deviations
}

Mingyang Wang • Yuehai Sun

Key Laboratory of Mechanism Theory and Equipment Design of Ministry of Education, Tianjin University, Tianjin 300072, China.

Corresponding author E-mail address: yuehaisun@tju.edu.cn (Yuehai Sun)

\begin{abstract}
:
To improve the meshing performance and increase the bearing capacity and service life of spiral gear pairs, the cutter head approximation machining method based on controlling topological deviations was proposed to solve the problem where line contact spiral bevel gears with tapered teeth depth cannot be directly machined by cutter heads. First, the mathematical model of line contact conjugate flanks was established, and meshing equations and conjugate flank equations of bevel gear pairs were derived. Second, the gear tooth flank was set as the datum tooth flank for priority machining, and the pinion theoretical tooth flank which is fully conjugate with the gear tooth flank and the pinion machining tooth flank matching with the gear were solved. Then, the geometric topological deviations model of the comparison between the pinion machining tooth flank and its theoretical tooth flank can be established. Finally, with the pinion machining tooth flank approaching its theoretical tooth flank as the modification, the additional cutting motions and machining compensation parameters of cutter heads were obtained to control the pinion machining tooth flank deviations and reduce them to the allowable deviations of its theoretical tooth flank. The contact simulation analysis and rolling test verified the correctness of the line contact conjugate flank model and feasibility of the cutter head approximation machining method.
\end{abstract}

\section{Key Word}

Spiral bevel gear; line contact; NC machining method; tooth flank mathematical model; contact simulation

\section{Introduction}

Spiral bevel gears can realize power and motion transmission for intersecting axes, which are the key part of mechanical transmission and are widely applied in many fields such as automobiles, construction machinery, and aerospace. According to the form of tooth depth, spiral bevel gears can be divided into constant and tapered teeth depths. Spiral bevel gears with constant teeth depth can be directly machined by cutter heads to form a pair of complete conjugate flank by the generating gear principle. However, when spiral bevel gears with tapered teeth depth are machined in the same way, to form the root surface while generating the flank, the cutter head axis should be perpendicular to the root cone instead of the pitch cone. As a 
result, the axes of the two cutter heads are not parallel when machining the gear and pinion, that is, both cutter surfaces cannot match each other, which makes the machined gear pairs unable to achieve conjugate engagement in theory.

Based on the local conjugate theory [1], with the aim of local contact for the mating flank, traditional Gleason technology realized artificially set local conjugate engagement of spiral bevel gears by force deformation. However, problems such as difficulty in adjusting the contact area and poor bearing capacity of the gear pairs remained. For the above problems, Gleason Company successively proposed the helix form method [2] and duplex helical method [3], which adjusted the position of the contact area by adding the helical feed motion to the gear and the pinion, respectively, during cutting. Litvin [4-6] presented the local synthesis, which overcame the problem where local conjugate theory did not control the second-order contact parameter of the tooth flank by presetting three second-order contact parameters at the reference point. Shih et al. [7, 8] developed a novel ease-off methodology for flank modification, which constructed the desired ease-off topographies by calculating and synthesizing the ease-off along the contact path from the predesigned transmission error and along the contact line from the predesigned bearing ratio. To identify the values of the machine tool settings required to obtain flank modifications in hypoid gears, Artoni et al. [9-12] solved the nonlinear least-squares formulation by the Levenberg-Marquardt method with a trust-region strategy. On this basis, an efficient methodology was presented to restore the designed functional properties of hypoid gears, that is, the gear deviations can be mapped into equivalent pinion deviations, added to those of the pinion itself, and cumulatively compensated for by applying corrective machine tool settings to the pinion. Nie et al. [13-15] established the pinion target tooth flank and modification mathematical model by adjusting the factors of tooth flank mismatch topography along five directions, which improved the meshing performance and correct contact area of spiral bevel gears. Mu et al. modified the tooth surface by using an arc blade instead of cutter heads, which reduced the maximum contact stress on the tooth surface and avoided tooth edge contact under misalignment or heavy load. Based on the highly flexible of universal five-axis milling machine tools, Alvare et al. [17] studied the complete machining process of the largesized spiral bevel gear and found the optimal cutting strategy in all strategies with different milling paths and scallop heights. Zhou et al. [18] reduced the machining error of the contact area through the optimization method of cutter position and orientation based on tooth flank model and NC programming technology. Xie established high accurate tooth surface based on a genuine face milling cutter geometric model, which laid down a ground for accurate tooth surface analysis. Sun et al $[19,20]$ analyzed the reason for the bias of tooth contact in the traditional generating method, and effectively improved the quality of tooth flank by adopting the spread-out helix modified roll.

However, in practical engineering applications, spiral bevel gear pairs machined based on local conjugate theory are more prone to damage, such as tooth flank contact fatigue, because of the small zone of action. Therefore, the research on the spiral bevel gear transmission based on line contact is a practicable way to obtain gear pairs with better meshing performance, higher bearing capacity and longer operation life. With the development of digital advanced manufacturing technology, the machining conditions for line contact spiral bevel gear pairs are already available, so that the design theory and manufacturing technology of spiral bevel gears 
should return to line contact conjugate engagement.

The free-form curved surface machining technology of the ball end milling cutter based on the NC machining center can machine line contact spiral bevel gear pairs, but the efficiency is too low. García-García et al. obtained bevel gears with exact spherical involute based on the additive manufacturing technology, but the bearing capacity is limited and cannot be mass produced. Taking the tooth flank design of spiral bevel gears with spherical involute as an example, Hong et al. [16] proposed a new cutting method based on the theory for designing the tooth profile of spiral bevel gear, which can process spherical involute tooth profile, but the tooth profile error is large in actual machining. Mao et al. [21] proposed a bevel gear machining method based on multi-axis CNC machine tools, which can machine various bevel gears by enveloping the generating flank through the tool generatrix. Sun et al. [22, 23] proposed a forming method of line contact spiral bevel gear pairs, which strictly follows the generating gear principle and can realize the dual machining of spiral bevel gears by using the gear machining tooth flank as the cutter surface of the pinion. However, both machining methods need to use finger-type cutters to realize their cutting motions, and their machining efficiencies are still lower than that of the cutter head machining method. In addition, when machining small-modulus gears, the cutting-edge strength is difficult to be ensure because the cutter size is too small.

To solve the problem where line contact spiral bevel gear pairs cannot be directly machined by cutter heads, the cutter head milling approximation machining method was proposed in this paper. That is, by controlling the geometric topological deviations between the pinion machining tooth flank and its theoretical tooth flank, the modification target where the pinion machining tooth flank approaches its theoretical tooth flank will be realized. First, the mathematical model of line contact conjugate flanks was established, and meshing equations and conjugate flank equations of bevel gear pairs were obtained. Second, the gear was set as the design datum for priority machining, and the gear machining tooth flank equation machined by the generating gear principle and the theoretical tooth flank equation of the pinion conjugated with the gear were solved. Then, based on obtained pinion theoretical tooth flank and the pinion machining tooth flank machined by the generating gear principle, the geometric topological deviations model of the comparison between two tooth flanks was established. Thirdly, with the pinion machining tooth flank approaching its theoretical tooth flank as the modification target, the additional cutting motions and machining compensation parameters of the cutter head that can control the pinion machining tooth flank deviations to reduce the allowable deviations of its theoretical tooth flank were determined. Finally, the NC cutting model of line contact spiral bevel gear pairs was obtained. The contact simulation analysis and rolling test verified the design theory and machining methods suitable for $\mathrm{NC}$ machining of line contact spiral bevel gear pairs.

\section{Mathematical model of line contact conjugate flanks}

The mathematical model of line contact conjugate flanks was established. As shown in Fig. 1, coordinate systems $S_{1}\left(x_{1}, y_{1}, z_{1}\right)$ and $S_{2}\left(x_{2}, y_{2}, z_{2}\right)$ are rigidly connected to the gear 1 and the gear 2, respectively. Auxiliary coordinate systems $S_{\mathrm{p}}\left(x_{\mathrm{p}}, y_{\mathrm{p}}, z_{\mathrm{p}}\right)$ and $S_{\mathrm{g}}\left(x_{\mathrm{g}}, y_{\mathrm{g}}, z_{\mathrm{g}}\right)$ are used to determine the positional relationship between gear 1 and gear 2 . According to the positional 
relationship between each coordinate system shown in Figure 1, the transformation matrix from coordinate system $S_{2}$ to $S_{1}$ can be obtained:

$$
\boldsymbol{M}_{12}\left(\varphi_{2}\right)=\boldsymbol{M}_{1 p}\left(\varphi_{1}, l_{1}\right) \boldsymbol{M}_{p g}(\eta, e) \boldsymbol{M}_{g 2}\left(\varphi_{2}, l_{2}\right)
$$

where $l_{1}$ and $l_{2}$ are the distances from the pitch apex to the crossing point of axes for gear 1 and gear 2, respectively. $e$ is the offset. $\varphi_{1}$ and $\varphi_{2}$ are the rotation angles of gear 1 and gear 2 , respectively. The rotation angle $\varphi_{1}$ can be represented as $\varphi_{1}=\varphi_{2} \cdot z_{2} / z_{1}$, where $z_{1}$ and $z_{2}$ are the number of teeth for gear 1 and gear 2, respectively.

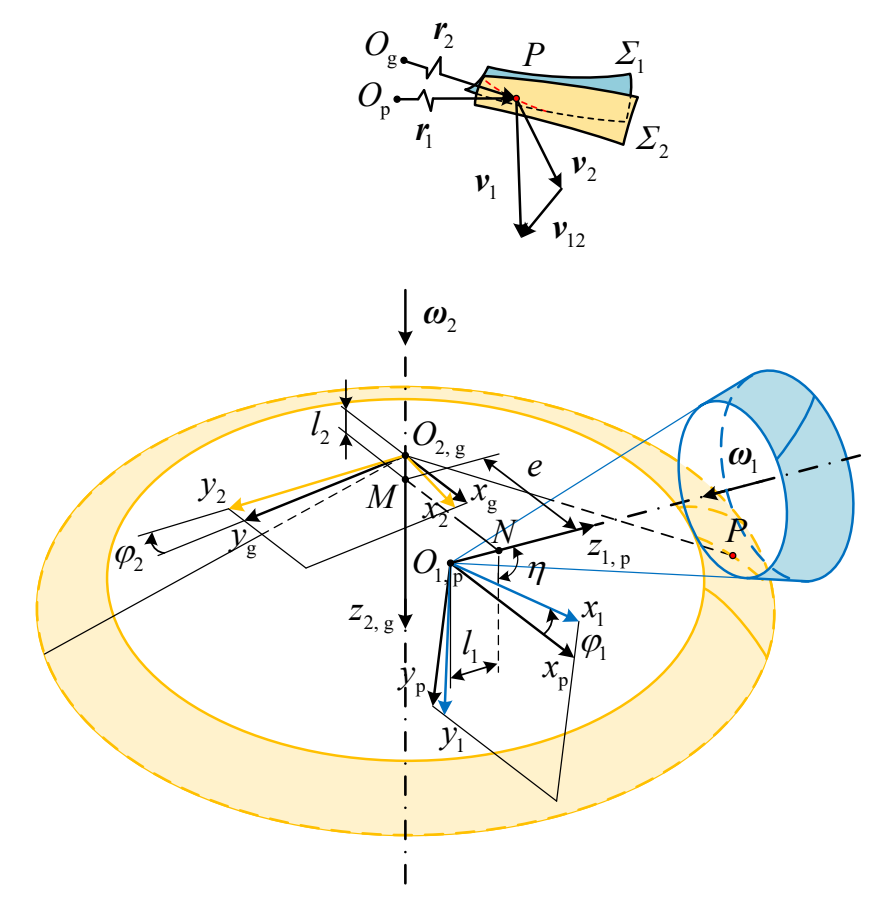

Fig. 1. Mathematical model of line contact conjugate flanks.

Let the position vector of any meshing point $P$ on the tooth flank $\Sigma_{2}$ be expressed in coordinate system $S_{2}$ as follows:

$$
\boldsymbol{r}_{2}^{(2)}=\boldsymbol{r}_{2}^{(2)}(v, w)=x_{2}(v, w) \boldsymbol{i}_{2}+y_{2}(v, w) \boldsymbol{j}_{2}+z_{2}(v, w) \boldsymbol{k}_{2}
$$

where $v$ and $w$ are the tooth flank parameters used to determine the position vector of point $P$.

The unit normal vector $\boldsymbol{n}_{2}^{(2)}$ at the point $P$ is expressed in coordinate system $S_{2}$ as follows:

$$
\begin{aligned}
\boldsymbol{n}_{2}^{(2)} & =\frac{\boldsymbol{N}_{2}^{(2)}}{\left|\boldsymbol{N}_{2}^{(2)}\right|}=\frac{\left[\partial \boldsymbol{r}_{2}^{(2)}(v, w) / \partial v\right] \times\left[\partial \boldsymbol{r}_{2}^{(2)}(v, w) / \partial w\right]}{\left|\left[\partial \boldsymbol{r}_{2}^{(2)}(v, w) / \partial v\right] \times\left[\partial \boldsymbol{r}_{2}^{(2)}(v, w) / \partial w\right]\right|} \\
& =\frac{N_{x 2}^{(2)} \boldsymbol{i}_{2}+N_{y 2}^{(2)} \boldsymbol{j}_{2}+N_{z 2}^{(2)} \boldsymbol{k}_{2}}{\sqrt{\left(N_{x 2}^{(2)}\right)^{2}+\left(N_{y 2}^{(2)}\right)^{2}+\left(N_{z 2}^{(2)}\right)^{2}}}
\end{aligned}
$$

where $N_{x_{2}}^{(2)}, N_{y_{2}}^{(2)}$ and $N_{z_{2}}^{(2)}$ are the components of normal vector $N_{2}^{(2)}$ on axes $x_{2}, y_{2}$ and $z_{2}$.

The relative motion velocity $\boldsymbol{v}_{12}^{(2)}$ at the meshing point $P$ in coordinate system $S_{2}$ can be represented as follows: 


$$
\boldsymbol{v}_{12}^{(2)}=\boldsymbol{v}_{1}^{(2)}-\boldsymbol{v}_{2}^{(2)}=\omega_{1}^{(2)} \times \boldsymbol{r}_{1}^{(2)}-\omega_{2}^{(2)} \times \boldsymbol{r}_{2}^{(2)}
$$

At meshing point $P$, the two conjugate flanks satisfy the following meshing equation:

$$
\boldsymbol{n}_{2}^{(2)} \cdot \boldsymbol{v}_{12}^{(2)}=0
$$

Eqs. (2) and (3) show that $\boldsymbol{n}_{2}^{(2)}$ is a function with parameters $v$ and $w$, and $\boldsymbol{v}_{12}^{(2)}$ is a function with parameters $v, w$ and $\varphi 2$. Therefore, Eq. (5) can be expressed as scalar functions:

$$
f_{12}\left(v, w, \varphi_{2}\right)=\boldsymbol{n}_{2}^{(2)} \cdot \boldsymbol{v}_{12}^{(2)}=0
$$

The equation for the instantaneous contact line on tooth flank $\Sigma_{2}$ can be obtained as follows:

$$
\left\{\begin{array}{l}
\boldsymbol{r}_{2}^{(2)}=\boldsymbol{r}_{2}^{(2)}(v, w) \\
\boldsymbol{n}_{2}^{(2)} \cdot \boldsymbol{v}_{12}^{(2)}=0
\end{array}\right.
$$

Eq. (7) is expressed as a Cartesian coordinate equation:

$$
\left\{\begin{array}{l}
x_{2}=x_{2}(v, w) \\
y_{2}=y_{2}(v, w) \\
z_{2}=z_{2}(v, w) \\
f_{12}\left(v, w, \varphi_{2}\right)=0
\end{array}\right.
$$

The equation for conjugate flank $\Sigma_{1}$ can be obtained by transforming Eq. (7) in coordinate system $S_{2}$ to $S_{1}$ :

$$
\left\{\begin{array}{l}
\boldsymbol{r}_{2}^{(2)}=\boldsymbol{r}_{2}^{(2)}(v, w) \\
\boldsymbol{n}_{2}^{(2)} \cdot \boldsymbol{v}_{12}^{(2)}=0 \\
\boldsymbol{r}_{1}^{(1)}=\boldsymbol{M}_{12}\left(\varphi_{2}\right) \boldsymbol{r}_{2}^{(2)}(v, w)
\end{array}\right.
$$

Eq. (9) is expressed as a Cartesian coordinate equation:

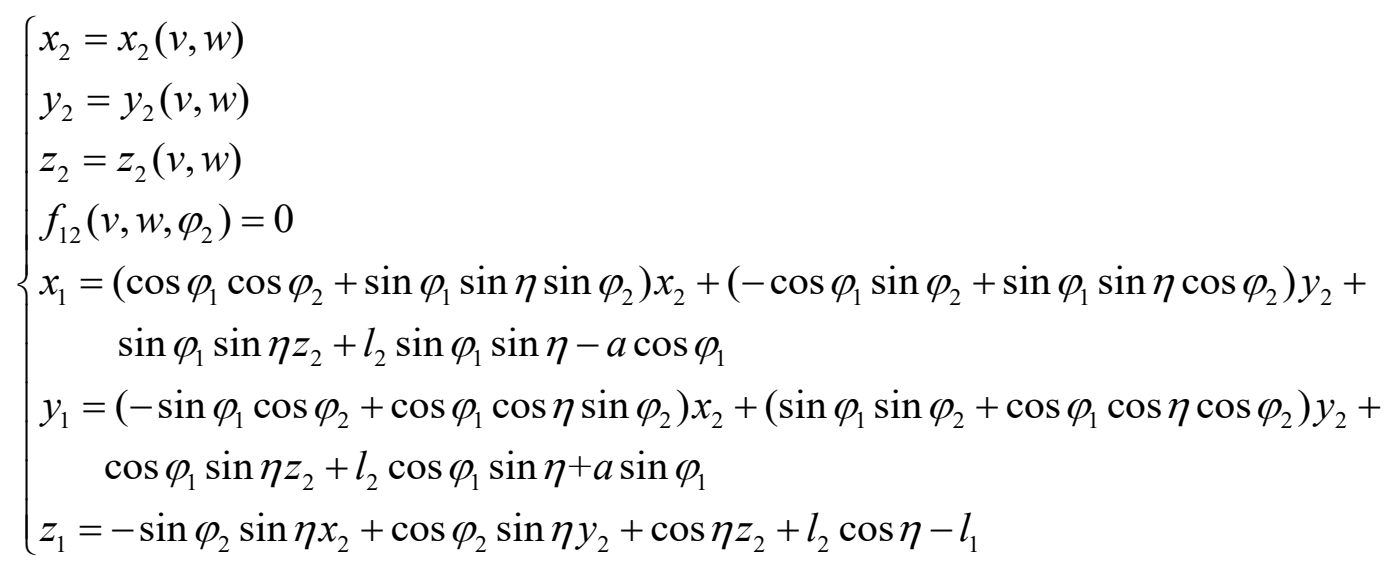

\section{Geometric topological deviations model}

Due to the large number of teeth and longer cutting time for the gear, to ensure machining efficiency, the gear tooth flank should be set as the datum tooth flank for priority machining. First, the machine tool cutting model was established, and the gear machining tooth flank equation based on the cutter head generating method was solved. Second, the pinion theoretical tooth flank equation, which is conjugate meshing with the gear machining tooth flank, was 
obtained by applying the mathematical model of line contact conjugate flanks. Then, based on the pinion theoretical tooth flank equation and the pinion machining tooth flank equation obtained by the generating gear principle, the geometric topological deviations model of the comparison between the machining tooth flank and theoretical tooth flank can be established.

\subsection{Machine tool cutting model}

The gear of a spiral bevel gear pair is usually machined by the forming method or generating method, and the pinion is often processed by the roll ratio modification method and tilting method. The roll ratio modification method requires the roll ratio modification mechanism to realize the regular speed changing of the roll ratio. Its machine tool cutting model is similar to the generating method, which only needs to change the roll ratio from constant to variable. The tilting method needs a machine tool with the tilt and swivel mechanisms to realize the changes in tilt angle and cutting position for the cutter head, with the addition of tilt and swivel coordinate systems relative to the generating method.

Considering the generality of the tooth flank model, when establishing the machine tool cutting model, the gear and the pinion will be machined by the generating method and tilting method, respectively. The generating method can be regarded as a special machine tool cutting model of the tilting method with the tilt and swivel mechanisms at the initial zero position. In other words, the tilt and swivel angles are both zero when the gear is machined by the generating method. Therefore, the cutting model of the cradle-type bevel gear milling machine with the tilt and swivel mechanisms was established, as shown in Fig. 2.

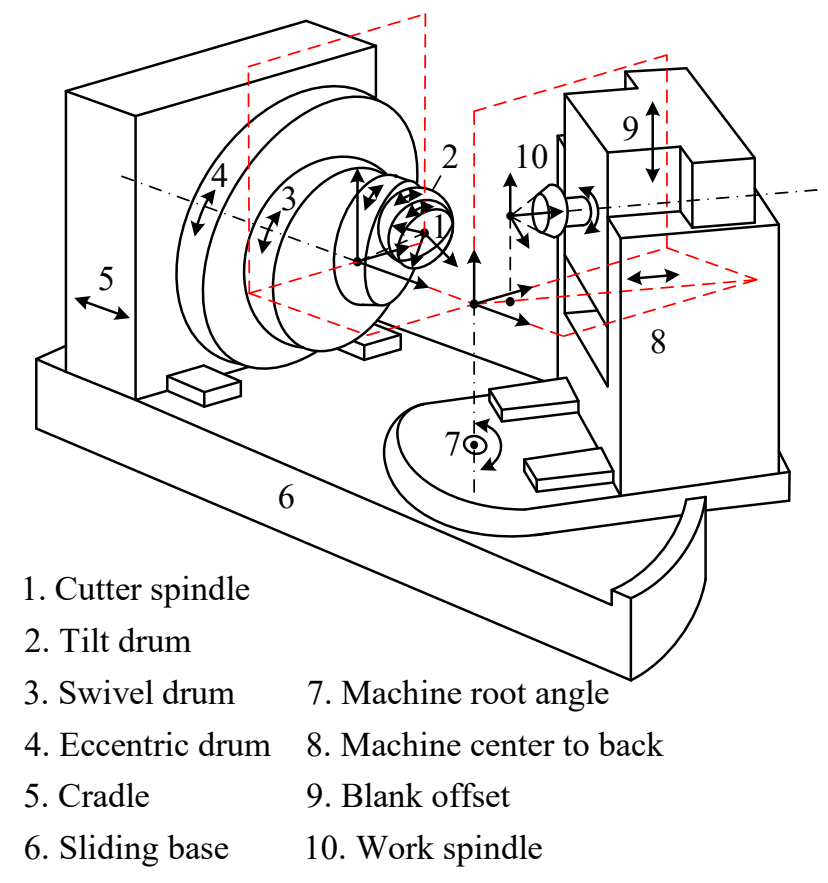

Fig. 2. Cutting model of the cradle-type bevel gear milling machine with the tilt and swivel mechanisms.

\subsection{Gear machining tooth flank equation}

Based on the above cutting model, the machining coordinate systems for the gear were established in Fig. 3, coordinate systems $S_{\mathrm{t}}\left(x_{\mathrm{t}}, y_{\mathrm{t}}, z_{\mathrm{t}}\right)$ and $S_{2}\left(x_{2}, y_{2}, z_{2}\right)$ are rigidly connected to the cutter head and the work gear, respectively. $S_{\mathrm{c}}$ represents the coordinate system of the 
generating gear, and $S_{0}$ represents the machine coordinate system. $S_{\mathrm{a}}, S_{\mathrm{b}}$ and $S_{\mathrm{g}}$ are auxiliary coordinate systems used to determine the positional relationship between the cutter head and the work gear. Transforming position vector $\boldsymbol{r}_{\mathrm{t}}^{(\mathrm{t})}$ of cutter surface $\Sigma_{\mathrm{t}}$ in coordinate system $S_{\mathrm{t}}$ to $S_{2}$, position vector $\boldsymbol{r}_{2}^{(2)}$ of gear machining tooth flank $\Sigma_{2}$ can be obtained in coordinate system $S_{2}$ :

$$
\left\{\begin{array}{l}
\boldsymbol{r}_{t}^{(t)}=\boldsymbol{r}_{t}^{(t)}\left(\boldsymbol{\xi}_{2}\right) \\
\boldsymbol{n}_{t}^{(t)}\left(\xi_{2}\right) \cdot \boldsymbol{v}_{2 t}^{(t)}\left(\xi_{2}, \lambda_{2}, \varphi_{c 2}\right)=0 . \\
\boldsymbol{r}_{2}^{(2)}=\boldsymbol{M}_{2 t}\left(\varphi_{2}, \lambda_{2}\right) \boldsymbol{r}_{t}^{(t)}\left(\boldsymbol{\xi}_{2}\right)
\end{array}\right.
$$

where $\boldsymbol{n}_{\mathrm{t}}^{(\mathrm{t})}\left(\boldsymbol{\xi}_{2}\right)$ and $\boldsymbol{v}_{2 \mathrm{t}}^{(\mathrm{t})}\left(\boldsymbol{\xi}_{2}, \boldsymbol{\lambda}_{2}, \varphi_{2}\right)$ represent the unit normal vector of the cutter surface and the relative motion velocity between the cutter head and the work gear in coordinate system $S_{\mathrm{t}}$, respectively. $\boldsymbol{M}_{2 \mathrm{t}}\left(\varphi_{2}, \lambda_{2}\right)$ represents the transformation matrix from coordinate system $S_{\mathrm{t}}$ to $S_{2}$. $\xi_{2}=\left(u_{2}, \theta_{2}, r_{02}, \alpha_{2}, W_{2}\right)$ are the cutter parameters of the gear. Here, the position parameters are represented by $u_{2}$ and $\theta_{2}$, the profile angle is represented by $\alpha_{2}$, the nominal radius by $r_{02}$, and the cutter point width by $W_{2} . \lambda_{2}=\left(\varphi_{\mathrm{c} 2}, S_{2}, q_{2}, i_{2} \mathrm{c}, \delta_{\mathrm{M} 2}, E_{2}, X_{2}, X_{\mathrm{B} 2}\right)$ represent the machining parameters of the gear tooth flank, including the rotation angle of generating gear $\varphi_{\mathrm{c} 2}$, the radial setting $S_{2}$, the initial cradle angle setting $q_{2}$, the roll ratio $i_{2 \mathrm{c}}$, the machine root angle $\delta_{\mathrm{M} 2}$, the vertical offset $E_{2}$, the increment of machine center to back $X_{2}$, the sliding base feed setting $X_{\mathrm{B} 2}$, and the rotation angle of the gear $\varphi_{2}$ which can be represented as $\varphi_{2}=i_{2 \mathrm{c}} \cdot \varphi_{\mathrm{c} 2}$. The above parameters are constant except for $u_{2}, \theta_{2}$ and $\varphi_{\mathrm{c} 2}$. Therefore, when solving the tooth flank points, the gear machining tooth flank equation can be regarded as an expression of the variables $u_{2}$, $\theta_{2}$ and $\varphi_{\mathrm{c} 2}$ for iterative solution.
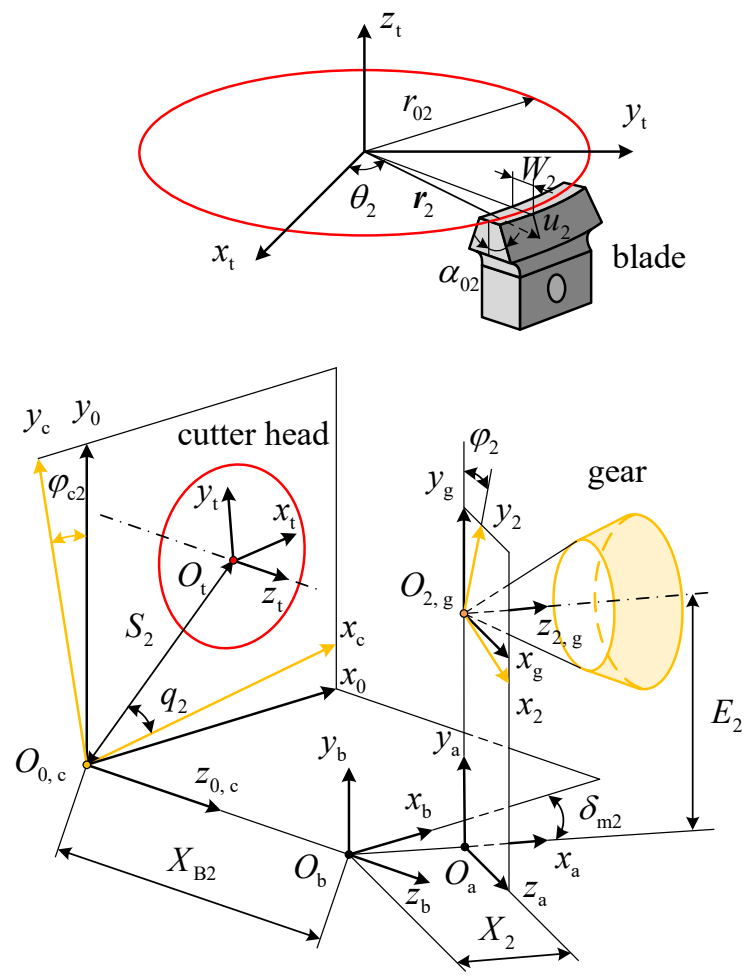

Fig. 3. Machining coordinate systems for the gear.

\subsection{Pinion theoretical tooth flank equation}

Transforming position vector $\boldsymbol{r}_{2}^{(2)}$ in coordinate system $S_{2}$ to $S_{1}$, position vector $\boldsymbol{r}_{0}^{(1)}$ of pinion 
theoretical tooth flank $\Sigma_{0}$ which is conjugate with gear machining tooth flank $\Sigma_{2}$ can be expressed as follows:

$$
\left\{\begin{array}{l}
\boldsymbol{r}_{t}^{(t)}=\boldsymbol{r}_{t}^{(t)}\left(\boldsymbol{\xi}_{2}\right) \\
\boldsymbol{n}_{t}^{(t)}\left(\boldsymbol{\xi}_{2}\right) \cdot \boldsymbol{v}_{2 t}^{(t)}\left(\boldsymbol{\xi}_{2}, \lambda_{2}, \varphi_{c 2}\right)=0 \\
\boldsymbol{r}_{2}^{(2)}=\boldsymbol{M}_{2 t}\left(\varphi_{2}, \lambda_{2}\right) \boldsymbol{r}_{t}^{(t)}\left(\boldsymbol{\xi}_{2}\right) \\
\boldsymbol{n}_{2}^{(2)}\left(\boldsymbol{\xi}_{2}, \lambda_{2}, \varphi_{2}\right) \cdot \boldsymbol{v}_{12}^{(2)}\left(\xi_{2}, \lambda_{2}, \varphi_{2}\right)=0 \\
\boldsymbol{r}_{0}^{(1)}=\boldsymbol{M}_{12}\left(\varphi_{1}, \eta, \varphi_{2}\right) \boldsymbol{r}_{2}^{(2)}
\end{array}\right.
$$

where $\boldsymbol{n}_{2}^{(2)}\left(\boldsymbol{\xi}_{2}, \lambda_{2}, \varphi_{2}\right)$ and $\boldsymbol{v}_{12}^{(2)}\left(\boldsymbol{\xi}_{2}, \boldsymbol{\lambda}_{2}, \varphi_{2}\right)$ represent the unit normal vector of the gear machining tooth flank and the relative motion velocity between the gear and pinion in coordinate system $S_{2}$, respectively. $\boldsymbol{M}_{12}\left(\varphi_{1}, \varphi_{2}\right)$ represents the transformation matrix from coordinate system $S_{2}$ to $S_{1}$. Since the transmission ratio of the spiral bevel gear pair is fixed, the pinion theoretical tooth flank equation can also be regarded as an expression of the variables $u_{2}, \theta_{2}$ and $\varphi_{\mathrm{c} 2}$.

\subsection{Pinion machining tooth flank equation}

The solution process of the pinion machining tooth flank equation is similar to that of the gear, but the tilt and swivel coordinate systems are added based on the generating method, for which it is necessary to re-establish the machining coordinate systems to solve it.

Based on the cutting model in Fig. 2, machining coordinate systems for the pinion were established in Fig. 4, coordinate systems $S_{\mathrm{t}}\left(x_{\mathrm{t}}, y_{\mathrm{t}}, z_{\mathrm{t}}\right)$ and $S_{2}\left(x_{1}, y_{1}, z_{1}\right)$ are rigidly connected to the cutter head and the work pinion, respectively. $S_{0}$ represents the machine coordinate system. Coordinate systems $S_{Q}, S_{\beta}, S_{J}$ and $S_{I}$ are rigidly connected to the cradle, eccentric, swivel and tilt drum, respectively. $S_{\mathrm{a}}, S_{\mathrm{b}}, S_{\mathrm{c}}, S_{\mathrm{d}}, S_{\mathrm{e}}$ and $S_{\mathrm{g}}$ are auxiliary coordinate systems used to determine the positional relationship between the cutter head and the work pinion. Transforming position vector $\boldsymbol{r}_{\mathrm{t}}^{(\mathrm{t})}$ of cutter surface $\Sigma_{\mathrm{t}}$ in coordinate system $S_{\mathrm{t}}$ to $S_{1}$, position vector $\boldsymbol{r}_{1}^{(1)}$ of pinion machining tooth flank $\Sigma_{1}$ in coordinate system $S_{1}$ can be obtained:

$$
\left\{\begin{array}{l}
\boldsymbol{r}_{t}^{(t)}=\boldsymbol{r}_{t}^{(t)}\left(\boldsymbol{\xi}_{1}\right) \\
\boldsymbol{n}_{t}^{(t)}\left(\boldsymbol{\xi}_{1}\right) \cdot \boldsymbol{v}_{1 t}^{(t)}\left(\boldsymbol{\xi}_{1}, \lambda_{1}, \varphi_{c 1}\right)=0 \\
\boldsymbol{r}_{1}^{(1)}=\boldsymbol{M}_{1 t}\left(\varphi_{1}, \lambda_{1}\right) \boldsymbol{r}_{t}^{(t)}\left(\boldsymbol{\xi}_{1}\right)
\end{array}\right.
$$

where $\boldsymbol{n}_{\mathrm{t}}^{(\mathrm{t})}\left(\boldsymbol{\xi}_{1}\right)$ and $\boldsymbol{v}_{1 \mathrm{t}}^{(\mathrm{t})}\left(\boldsymbol{\xi}_{1}, \lambda_{1}, \varphi_{\mathrm{c} 1}\right)$ represent the unit normal vector of the cutter surface and the relative motion velocity between the cutter head and work pinion in coordinate system $S_{\mathrm{t}}$, respectively. $\boldsymbol{M}_{1 \mathrm{t}}\left(\varphi_{1}, \lambda_{1}\right)$ represents the transformation matrix from coordinate system $S_{\mathrm{t}}$ to $S_{1}$. $\xi_{1}=\left(u_{1}, \theta_{1}, r_{1}, \alpha_{1}\right)$ are the cutter parameters of the pinion. Here, the position parameters are represented by $u_{1}$ and $\theta_{1}$, the profile angle is represented by $\alpha_{1}$ and the cutter point radius by $r_{1}$. $\lambda_{2}=\left(Q, \beta, I, J, \delta_{\mathrm{M} 1}, E_{1}, X_{1}, X_{\mathrm{B} 1}, i_{1 \mathrm{c}}\right)$ represent the machining parameters of the pinion tooth flank, including the cradle angle $Q$, which is the sum of the initial cradle angle $Q_{0}$ and the rotation angle of the generating gear $\varphi_{\mathrm{c} 1}$, the eccentric angle $\beta$, the swivel angle $J$, the tilt angle $I$, the machine root angle $\delta \mathrm{M} 1$, the vertical offset $E_{1}$, the increment of the machine center to the back $X_{1}$, the sliding base feed setting $X_{\mathrm{B} 1}$, the roll ratio $i_{1}$, and the rotation angle of pinion $\varphi_{1}$, which satisfies the relation $\varphi_{1}=i_{1 \mathrm{c}} \cdot \varphi_{\mathrm{c} 1}$. Similar to the gear machining tooth flank equation, the pinion machining tooth flank equation can be regarded as an expression of the variables $u_{1}, \theta_{1}$ and $\varphi_{\mathrm{c} 1}$. 

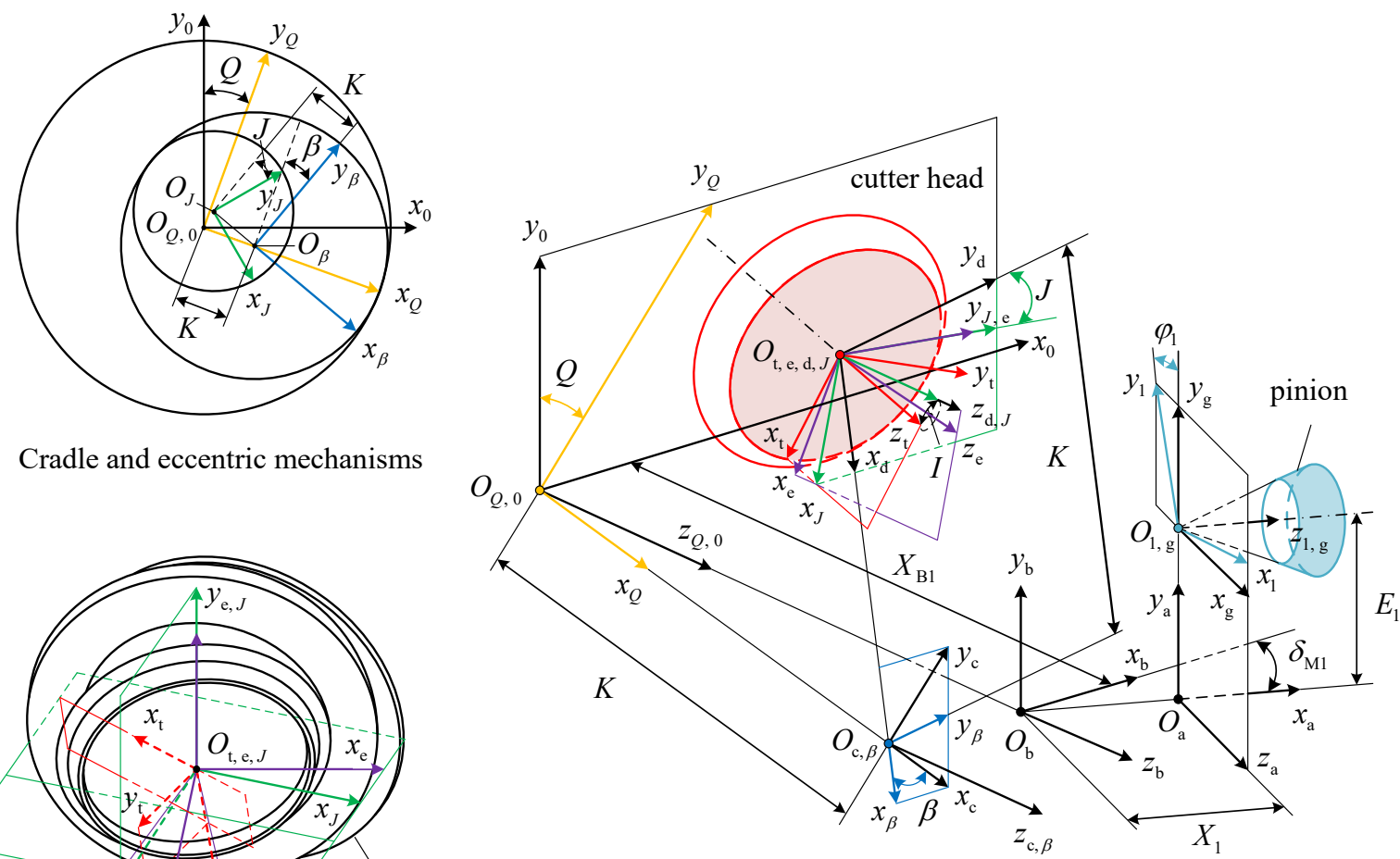

Cradle and eccentric mechanisms

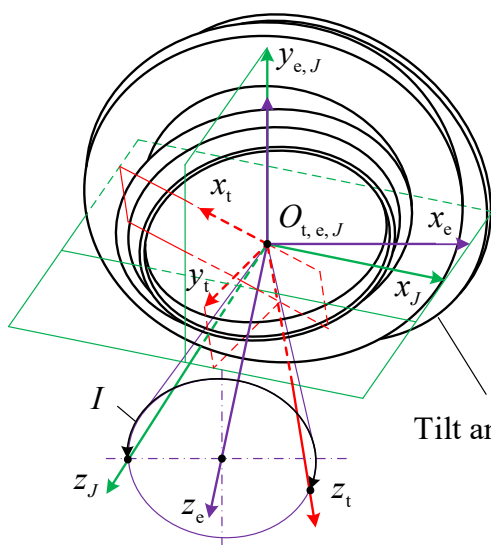

Tilt and swivel mechanisms

Fig. 4. Machining coordinate systems for the pinion

\subsection{Geometric topological deviations model}

According to the obtained pinion theoretical tooth flank $\Sigma_{0}$ and machining tooth flank $\Sigma_{1}$, a 3D model of both tooth flanks on the same pinion root cone was established. As seen from Eq. (13), pinion theoretical tooth flank $\Sigma_{0}$ is the secondary enveloping surface of cutter surface $\Sigma_{\mathrm{t}}$ (cutter surface $\Sigma_{\mathrm{t}}$ - gear machining tooth flank $\Sigma_{2}$ - pinion theoretical tooth flank $\Sigma_{0}$ ), and pinion machining tooth flank $\Sigma_{1}$ was directly enveloped by cutter surface $\Sigma_{\mathrm{t}}$ (cutter surface $\Sigma_{\mathrm{t}}$ - pinion machining tooth flank $\Sigma_{1}$ ) so that the variable parameters $u, \theta$ and $\varphi$ at each tooth flank point are generally not the same. As a result, the $3 \mathrm{D}$ model of both tooth flanks on the same pinion root cone will have an angular offset, as shown in Fig. 5.
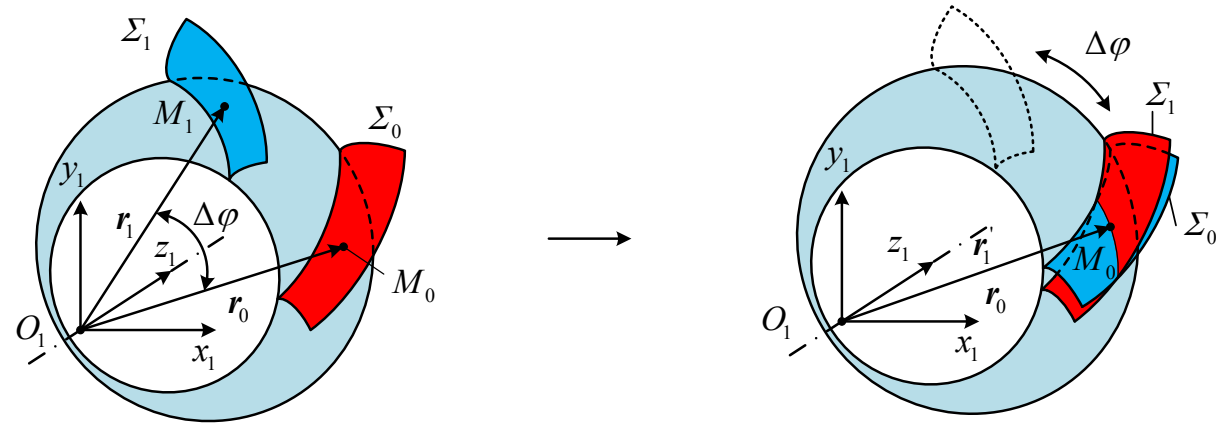

Fig. 5 Positional relationship between the pinion machining tooth flank and its theoretical tooth flank on the same root cone 
To solve the geometric topological deviations between the two tooth flanks, pinion machining tooth flank $\Sigma_{1}$ should be rotated by $\Delta \varphi$ around its axis $\mathrm{z}_{1}$ so that its midpoint will coincide with the midpoint of the theoretical tooth flank $\Sigma_{0}$. The pinion machining tooth flank $\Sigma_{1}$ after rotation can be expressed as follows:

$$
\boldsymbol{r}_{1}^{(1)^{\prime}}=\boldsymbol{M}(\Delta \varphi) \boldsymbol{r}_{1}^{(1)}
$$

here,

$$
\boldsymbol{M}(\Delta \varphi)=\left[\begin{array}{cccc}
\cos \Delta \varphi & -\sin \Delta \varphi & 0 & 0 \\
\sin \Delta \varphi & \cos \Delta \varphi & 0 & 0 \\
0 & 0 & 1 & 0 \\
0 & 0 & 0 & 1
\end{array}\right]
$$

where $\boldsymbol{M}(\Delta \varphi)$ is the transformation matrix from position vector $\boldsymbol{r}_{1}^{(1)}$ to $\boldsymbol{r}_{1}^{(1)^{\prime}}$.

According to the pinion machining tooth flank $\Sigma_{1}$ after rotation and the theoretical tooth flank $\Sigma_{0}$, the geometric topology deviations model can be established, as shown in Fig. 6 . The coordinates of the pinion machining tooth flank point before rotation are set as $\left(x_{1}, y_{1}, z_{1}\right)$, and the coordinates $\left(x_{1}^{\prime}, y_{1}^{\prime}, z_{1}^{\prime}\right)$ after rotation should be expressed as follows:

$$
\left\{\begin{array}{l}
x_{1}^{\prime}=x_{1} \cos \Delta \varphi-y_{1} \sin \Delta \varphi \\
y_{1}^{\prime}=x_{1} \sin \Delta \varphi+y_{1} \cos \Delta \varphi \\
z_{1}^{\prime}=z_{1}
\end{array}\right.
$$

The unit normal vector $\boldsymbol{n}_{1}^{\prime}$ at $\left(x_{1}^{\prime}, y_{1}^{\prime}, z_{1}^{\prime}\right)$ can be obtained by transforming the unit normal vector $\boldsymbol{n}_{\mathrm{t}}$ of cutter surface $\Sigma_{t}$ in coordinate system $S_{\mathrm{t}}$ to $S_{1}$ :

$$
\boldsymbol{n}_{1}^{(1) '}=\boldsymbol{L}(\Delta \varphi) \boldsymbol{L}_{1 t}\left(\varphi_{1}, \lambda_{1}\right) \boldsymbol{n}_{t}^{(t)}\left(u_{1}, \theta_{1}\right)
$$

where $\boldsymbol{L}(\Delta \varphi)$ and $\boldsymbol{L}_{1 \mathrm{t}}\left(\varphi_{1}, \lambda_{1}\right)$ represent the transformation matrices from normal vector $\boldsymbol{n}_{\mathrm{t}}$ to $\boldsymbol{n}$ i, which are third-order submatrices of transformation matrix $\boldsymbol{M}(\Delta \varphi)$ and $\boldsymbol{M}_{1 \mathrm{t}}\left(\varphi_{1}, \lambda_{1}\right)$ removing the elements of fourth row and fourth column, respectively. The coordinates of unit normal vector $\boldsymbol{n}_{1}^{\prime}$ are expressed as $\left(n_{x 1}^{\prime}, n_{y 1}^{\prime}, n_{z 1}^{\prime}\right)$, where $n_{x 1}^{\prime}, n_{y 1}^{\prime}$ and $n_{z 1}^{\prime}$ are the components on axes $x_{1}, y_{1}$ and $z_{1}$.

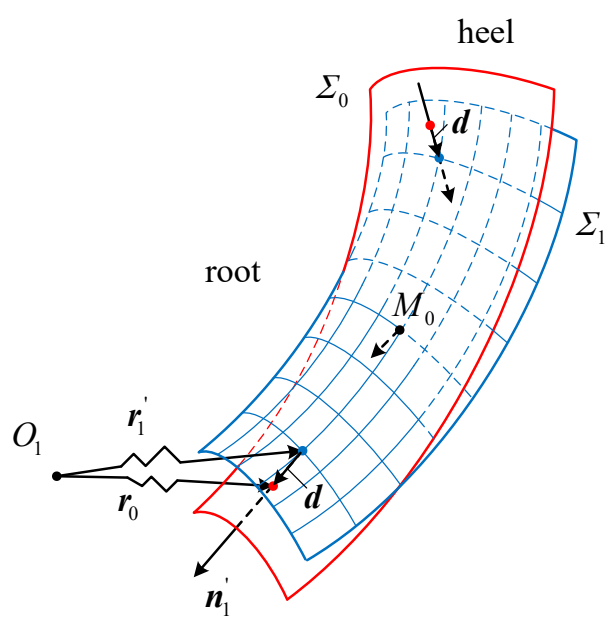

Fig. 6. Geometric topological deviations model of the comparison between the pinion machining tooth 
flank after rotation and its theoretical tooth flank.

Any point $\left(x_{1}^{\prime}, y_{1}^{\prime}, z_{1}^{\prime}\right)$ on pinion machining tooth flank $\Sigma_{1}$ to intersect theoretical tooth flank $\Sigma_{0}$ along the direction of unit normal vector $\boldsymbol{n}_{1}^{\prime}$ is set at the corresponding point $\left(x_{0}, y_{0}, z_{0}\right)$. The relationship between them can be expressed as follows:

$$
\frac{x_{0}-x_{1}^{\prime}}{n_{x_{1}}^{\prime}}=\frac{y_{0}-y_{1}^{\prime}}{n_{y_{1}}^{\prime}}=\frac{z_{0}-z_{1}^{\prime}}{n_{z_{1}}^{\prime}}
$$

Substituting Eqs. (15) and (16) into Eq. (17), the coordinate values of the corresponding point $\left(x_{0}, y_{0}, z_{0}\right)$ on pinion theoretical tooth flank can be solved. Then, the deviation $\Delta d$ between any point on pinion machining tooth flank $\Sigma_{1}$ and its corresponding point on theoretical tooth flank $\Sigma_{0}$ can be expressed as follows:

$$
\Delta d=\left(x_{0}-x_{1}^{\prime}, y_{0}-y_{1}^{\prime}, z_{0}-z_{1}^{\prime}\right) \cdot\left(n_{x_{1}}^{\prime}, n_{y_{1}}^{\prime}, n_{z_{1}}^{\prime}\right)^{\mathrm{T}}
$$

Eq. (18) is transformed into vector form:

$$
\boldsymbol{d}\left(\boldsymbol{\xi}_{1}, \lambda_{1}\right)=\left[\boldsymbol{r}_{0}\left(\boldsymbol{\xi}_{2}, \lambda_{2}\right)-\boldsymbol{r}_{1}^{\prime}\left(\boldsymbol{\xi}_{1}, \lambda_{1}\right)\right] \cdot \boldsymbol{n}_{1}^{\prime}\left(\boldsymbol{\xi}_{1}, \lambda_{1}\right)
$$

\section{Cutter head milling approximation method}

\subsection{Additional cutting motions}

To enable the machined pinion tooth flank to more accurately approximate its line contact theoretical tooth flank, additional cutting motions should be added to the cutter head in the process of pinion machining flank modification. Based on the obtained pinion machining tooth flank equation of the tilting method, the roll ratio can be modified to make the relationship between the rotation angle of the generating gear and the work pinion satisfy the modification polynomial as follows:

$$
\varphi_{1}=i_{1 c}\left(\varphi_{c 1}-C_{0} \varphi_{c 1}^{2}-D_{0} \varphi_{c 1}^{3}\right)
$$

where $C_{0}$ and $D_{0}$ represent the second-order ratio and third-order ratio, respectively, and their initial values can be set to zero.

Substituting Eq. (20) into Eq. (13), the pinion machining tooth flank equation can be reestablished:

$$
\left\{\begin{array}{l}
\boldsymbol{r}_{t}^{(t)}=\boldsymbol{r}_{t}^{(t)}\left(\xi_{1}\right) \\
\boldsymbol{n}_{t}^{(t)}\left(\xi_{1}\right) \cdot \boldsymbol{v}_{1 t}^{(t)}\left(\xi_{1}, \lambda_{1}, \varphi_{c 1}\right)=0 \\
\boldsymbol{r}_{1}^{(1)}=\boldsymbol{M}_{1 t}\left(\varphi_{1}, \lambda_{1}\right) \boldsymbol{r}_{t}^{(t)}\left(\xi_{1}\right) \\
\varphi_{1}=i_{1 c}\left(\varphi_{c 1}-C_{0} \varphi_{c 1}^{2}-D_{0} \varphi_{c 1}^{3}\right)
\end{array}\right.
$$

The geometric topology deviations model and the additional cutting motions of the cutter head were obtained. Then, with the pinion machining tooth flank approaching its theoretical tooth flank as the goal, the machining compensation parameters of the cutter head were obtained to control the machining tooth flank deviations and reduce them to the allowable deviations.

Since the nominal cutter radius and profile angle have been standardized, cutter parameters $\xi_{1}$ should be kept unchanged without increasing the cost of cutter manufacturing, and only 
machining parameters $\lambda_{1}$ should be modified. Therefore, the deviations should be simplified from the expression $\boldsymbol{d}\left(\xi_{1}, \lambda_{1}\right)$ to expression $\boldsymbol{d}\left(\lambda_{1}\right)$ containing only parameters $\lambda_{1}$, and the deviations of all the tooth flank points can be expressed as a vector:

$$
d\left(\lambda_{1}\right)=\left[d_{1}\left(\lambda_{1}\right), d_{2}\left(\lambda_{1}\right), \cdots, d_{k}\left(\lambda_{1}\right)\right]
$$

Taking machining parameters $\lambda_{1}$ as the optimization variable and the minimum square sum of the deviations $\boldsymbol{d}\left(\lambda_{1}\right)$ as the goal, the least square method optimization model can be established:

$$
\min f\left(\lambda_{1}\right)=\frac{1}{2} d\left(\lambda_{1}\right)^{\mathrm{T}} d\left(\lambda_{1}\right)
$$

The Levenberg-Marquardt method with a trust-region strategy is used to solve the optimization model. Generally, the initial deviations between the pinion machining tooth flank and its theoretical tooth flank are relatively large. Directly using the iterative method to modify machining parameters $\lambda_{1}$ will cause a large offset of the cutter relative to the initial position, that is, interference or deviation with the work pinion. To make the modified machining parameters have practical engineering significance, the initial deviations can be reduced by setting a deviation default value in advance, that is, some of the machining parameters are modified in advance so that the cutter head and the work pinion do not offset along the $z$ axis of the machine.

The influence of each tooth flank machining parameter on the relative position between the cutter and work pinion is analyzed. As shown in Fig. 7, the parameters that can prevent the cutter and the work pinion from being offset along the $z$ axis of the machine include $Q, \beta, E_{1}$, $i_{1 \mathrm{c}}, C_{0}$ and $D_{0}$. Therefore, the machining parameters to be modified in advance are $\boldsymbol{\rho}_{1}=[Q, \beta$, $\left.E_{1}, i_{1 \mathrm{c}}, C_{0}, D_{0}\right]$.
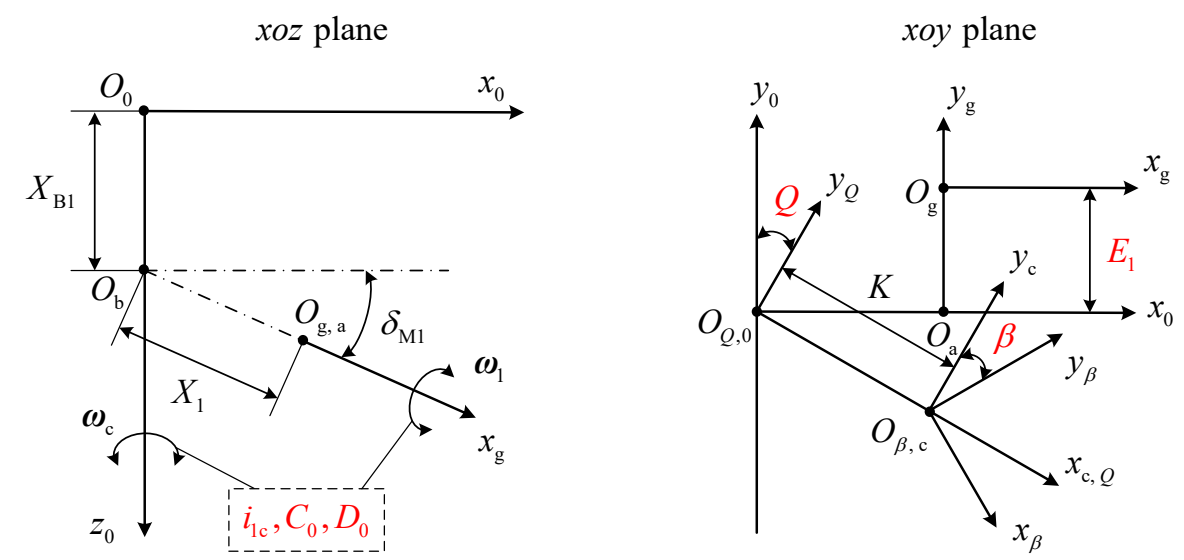

Fig. 7 Relative motion between the cutter head and work pinion

Then, with premodified machining parameters $\boldsymbol{\rho}_{1}$ as the optimization variable and the minimum square sum of tooth flank deviations $\boldsymbol{d}\left(\boldsymbol{\rho}_{1}\right)$ as the goal, the least square optimization model can be established as follows:

$$
\min f\left(\boldsymbol{\rho}_{1}\right)=\frac{1}{2} \boldsymbol{d}\left(\boldsymbol{\rho}_{1}\right)^{\mathrm{T}} \boldsymbol{d}\left(\boldsymbol{\rho}_{1}\right)
$$

The premodified machining parameters that reduce the deviation below the default value are solved, and the premodified deviations are obtained as $\boldsymbol{d}_{\rho}\left(\lambda_{1}\right)$. Then, the minimum sum of squares of $\boldsymbol{d}_{\rho}\left(\lambda_{1}\right)$ is taken as the goal and substituted into Eq. (23) to re-establish the 
optimization model:

$$
\min f\left(\lambda_{1}\right)=\frac{1}{2} \boldsymbol{d}_{p}\left(\lambda_{1}\right)^{\mathrm{T}} \boldsymbol{d}_{p}\left(\lambda_{1}\right)
$$

With such step-by-step modification by the above method, the machining compensation parameters that can satisfy the requirement of controlling the deviations and reducing them to the allowable deviations can be obtained to realize the effective approximation of the pinion machining tooth flank to its theoretical tooth flank. In addition, the approximation process is shown in Fig. 8.

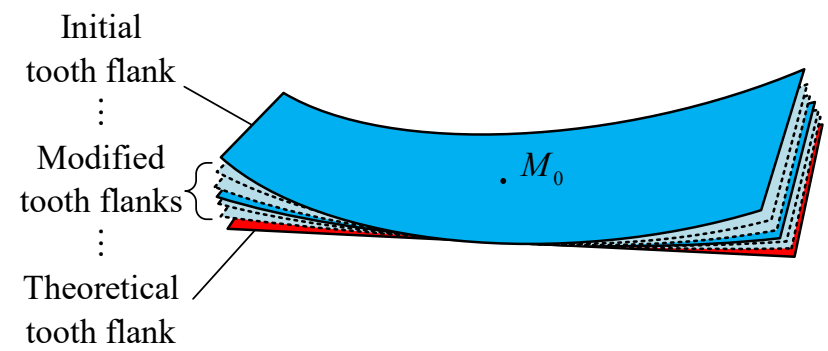

Fig. 8 Approximation process of initial pinion machining tooth flank approaching its theoretical tooth flank

\subsection{NC cutting model}

In the cutting process of the pinion, the "roll ratio modification" cutting motion is added to the cutter head based on the tilting method, while the traditional cradle-type machine tool is limited by the mechanical structure and cannot realize "tilting" and "roll ratio modification" cutting motions at the same time. Therefore, it is necessary to convert pinion machining parameters obtained based on the machine cutting model shown in Fig. 2 to the NC machine.

The tilting method requires a five-axis $\mathrm{CNC}$ machine with three translational axes (X, Y, and $\mathrm{Z}$ ) and two rotational axes (A, B) to realize its cutting motion, in which the $\mathrm{X}, \mathrm{Y}, \mathrm{Z}$ and $\mathrm{B}$ axes are used to realize the motion of the cradle with the tilt and swivel mechanism, and the $A$ axis realizes the constant rotational motion of the work pinion axis. The roll ratio modification method requires a four-axis $\mathrm{CNC}$ machine with three translational axes $(\mathrm{X}, \mathrm{Y}, \mathrm{Z})$ and one rotational axis $\mathrm{A}$ to realize its cutting motion, in which the $\mathrm{X}, \mathrm{Y}$, and $\mathrm{Z}$ axes are used to realize the constant rotational motion of the cradle, and the A axis makes variable-speed rotational motion so that the rotation angle of the generating gear and work pinion satisfies Eq. (20) to achieve the function of the roll ratio modification mechanism.

According to the above analysis, the cutting motion of the pinion can be realized based on three rectilinear motions and two rotational motions, that is, the $\mathrm{X}, \mathrm{Y}, \mathrm{Z}$ and $\mathrm{B}$ axes are used to realize the motion of the cradle with the tilt and swivel mechanism, and the A axis makes variable-speed rotational motion so that the rotation angle of the generating gear and work pinion satisfies Eq. (20).

The cutting model of the five-axis NC machine and the machining coordinate systems for NC cutting model were established, as shown in Fig. 9. Here, coordinate systems $S_{\mathrm{t}}\left(x_{\mathrm{t}}, y_{\mathrm{t}}, z_{\mathrm{t}}\right)$ and $S_{\mathrm{w}}\left(x_{\mathrm{w}}, y_{\mathrm{w}}, z_{\mathrm{w}}\right)$ are rigidly connected to the cutter head and the work pinion, respectively. $S_{0}$, $S_{1}$ and $S_{2}$ are auxiliary coordinate systems used to determine the positional relationship between the cutter head and the work pinion. 

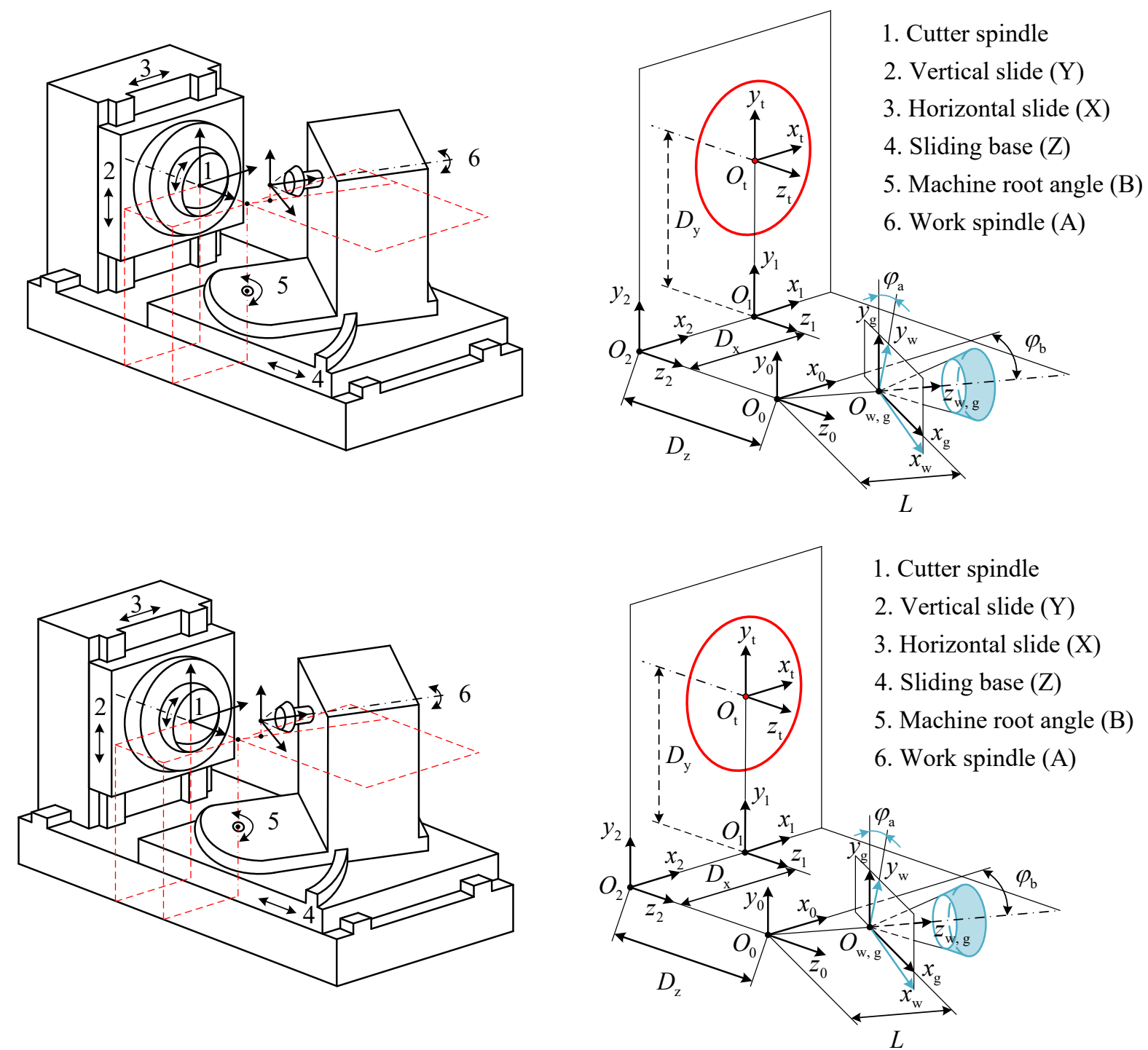

Fig. 9 Cutting model and machining coordinate systems of the five-axis $\mathrm{NC}$ machine

Position vector $\boldsymbol{r}_{\mathrm{t}}^{(\mathrm{t})}$ of cutter surface $\Sigma_{t}$ in coordinate system $S_{\mathrm{t}}$ is transformed to $S_{\mathrm{w}}$, and then, position vector $\boldsymbol{r}_{\mathrm{w}}^{(\mathrm{w})}$ of pinion machining tooth flank $\Sigma_{w}$ in coordinate system $S_{w}$ can be obtained:

$$
\boldsymbol{r}_{w}^{(w)}=\boldsymbol{M}_{w t}\left(D_{x}, D_{y}, D_{z}, \varphi_{a}, \varphi_{b}\right) \boldsymbol{r}_{t}^{(t)}\left(\boldsymbol{\xi}_{t}\right)
$$

where $\boldsymbol{M}_{\mathrm{wt}}$ is the transformation matrix from coordinate system $S_{\mathrm{t}}$ to $S_{\mathrm{w}}, D_{x}, D_{y}$ and $D_{z}$ represent the moving distances of three rectilinear motions, and $\varphi_{\mathrm{a}}, \varphi_{\mathrm{b}}$ represent the rotation angles of two rotational motions.

Since the positional relationship between the cutter head and the work pinion should be the same in two different machine tools, the coordinate transformation matrices in both machine tools should be equal, as shown in the following relation:

$$
\boldsymbol{M}_{1 t}\left(\varphi_{1}, \lambda_{1}\right)=\boldsymbol{M}_{w t}\left(D_{x}, D_{y}, D_{z}, \varphi_{a}, \varphi_{b}\right)
$$

where matrix $\boldsymbol{M}_{1 \mathrm{t}}$ is determined by pinion machining parameters $\lambda_{1}$ and pinion rotation angle $\varphi_{1}$. Because the parameters $\lambda_{1}$ are constant and the relationship between the rotation angles of the pinion and generating gear satisfies Eq. (20), the elements of matrix $\boldsymbol{M}_{1 \mathrm{t}}$ can be expressed as functions containing only rotation angle of generating gear $\varphi_{\mathrm{c}}$ : 


$$
\boldsymbol{M}_{1 t}=\left[\begin{array}{cccc}
f_{11}\left(\varphi_{c}\right) & f_{12}\left(\varphi_{c}\right) & f_{13}\left(\varphi_{c}\right) & f_{14}\left(\varphi_{c}\right) \\
f_{21}\left(\varphi_{c}\right) & f_{22}\left(\varphi_{c}\right) & f_{23}\left(\varphi_{c}\right) & f_{24}\left(\varphi_{c}\right) \\
f_{31}\left(\varphi_{c}\right) & f_{32}\left(\varphi_{c}\right) & f_{33}\left(\varphi_{c}\right) & f_{34}\left(\varphi_{c}\right) \\
0 & 0 & 0 & 1
\end{array}\right]
$$

Substituting Eqs. (26) and (27) into Eq. (28), the motion equations of each axis in the NC machine tool can be solved as follows:

$$
\left\{\begin{aligned}
f_{b}\left(\varphi_{c}\right) & =\sin ^{-1}\left(-f_{33}\left(\varphi_{c}\right)\right) \\
f_{a}\left(\varphi_{c}\right) & =\tan ^{-1}\left(-f_{23}\left(\varphi_{c}\right) / f_{13}\left(\varphi_{c}\right)\right) \\
f_{y}\left(\varphi_{c}\right) & =f_{14}\left(\varphi_{c}\right) \cdot \sin \left(f_{a}\left(\varphi_{c}\right)\right)+f_{24}\left(\varphi_{c}\right) \cdot \cos \left(f_{a}\left(\varphi_{c}\right)\right) \\
f_{z}\left(\varphi_{c}\right) & =\left(f_{24}\left(\varphi_{c}\right) \cdot \sin \left(f_{a}\left(\varphi_{c}\right)\right)-f_{14}\left(\varphi_{c}\right) \cdot \cos \left(f_{a}\left(\varphi_{c}\right)\right)\right) \\
& \times \cos \left(f_{b}\left(\varphi_{c}\right)\right)+\left(f_{34}\left(\varphi_{c}\right)-L\right) \cdot \sin \left(f_{b}\left(\varphi_{c}\right)\right) \\
f_{x}\left(\varphi_{c}\right) & =\left(f_{24}\left(\varphi_{c}\right) \cdot \sin \left(f_{a}\left(\varphi_{c}\right)\right)-f_{14}\left(\varphi_{c}\right) \cdot \cos \left(f_{a}\left(\varphi_{c}\right)\right)\right) \\
& \times \sin \left(f_{b}\left(\varphi_{c}\right)\right)-\left(f_{34}\left(\varphi_{c}\right)-L\right) \cdot \cos \left(f_{b}\left(\varphi_{c}\right)\right)
\end{aligned}\right.
$$

where $f_{\mathrm{a}}\left(\varphi_{\mathrm{c}}\right), f_{\mathrm{b}}\left(\varphi_{\mathrm{c}}\right), f_{\mathrm{x}}\left(\varphi_{\mathrm{c}}\right), f_{\mathrm{y}}\left(\varphi_{\mathrm{c}}\right)$ and $f_{\mathrm{z}}\left(\varphi_{\mathrm{c}}\right)$ represent the motion functions of $\varphi_{\mathrm{a}}, \varphi_{\mathrm{b}}, D_{x}, D_{y}$ and $D_{z}$, respectively, with rotation angle of generating gear $\varphi_{\mathrm{c}}$. By setting the value of $\varphi_{\mathrm{c}}$ and substituting it into Eq. (29), the instantaneous machine point position corresponding to each axis of the NC machine tool can be obtained, and then the cutting motion planning of the line contact spiral bevel gear pair can be realized.

\section{Case analysis and cutting test}

\subsection{D model of the spiral bevel gear pair}

Taking a pair of spiral bevel gear pairs with tapered teeth as the example pairs, the case analysis and cutting test were carried out on the drive side (gear convex and pinion concave). Table 1 shows the basic parameters of the example pair, from which the initial machining parameters of the example gear and pinion were determined and were listed in Table 2 and Table 3, respectively.

Table 1 Basic parameters for the example pair

\begin{tabular}{ccc}
\hline Item & Pinion & Ring gear \\
\hline Outer module $(\mathrm{mm})$ & 4 & 4 \\
Pressure angle $\left({ }^{\circ}\right)$ & 20 & 20 \\
Spiral angle $\left(^{\circ}\right)$ & 35 L.H. & 35 R.H. \\
Number of teeth & 13 & 43 \\
Pitch angle $\left(^{\circ}\right)$ & 16.821 & 73.179 \\
Face angle $\left(^{\circ}\right)$ & 20.369 & 74.922 \\
Root angle $\left({ }^{\circ}\right)$ & 15.078 & 69.631 \\
Outer diameter $(\mathrm{mm})$ & 61.223 & 173.147
\end{tabular}




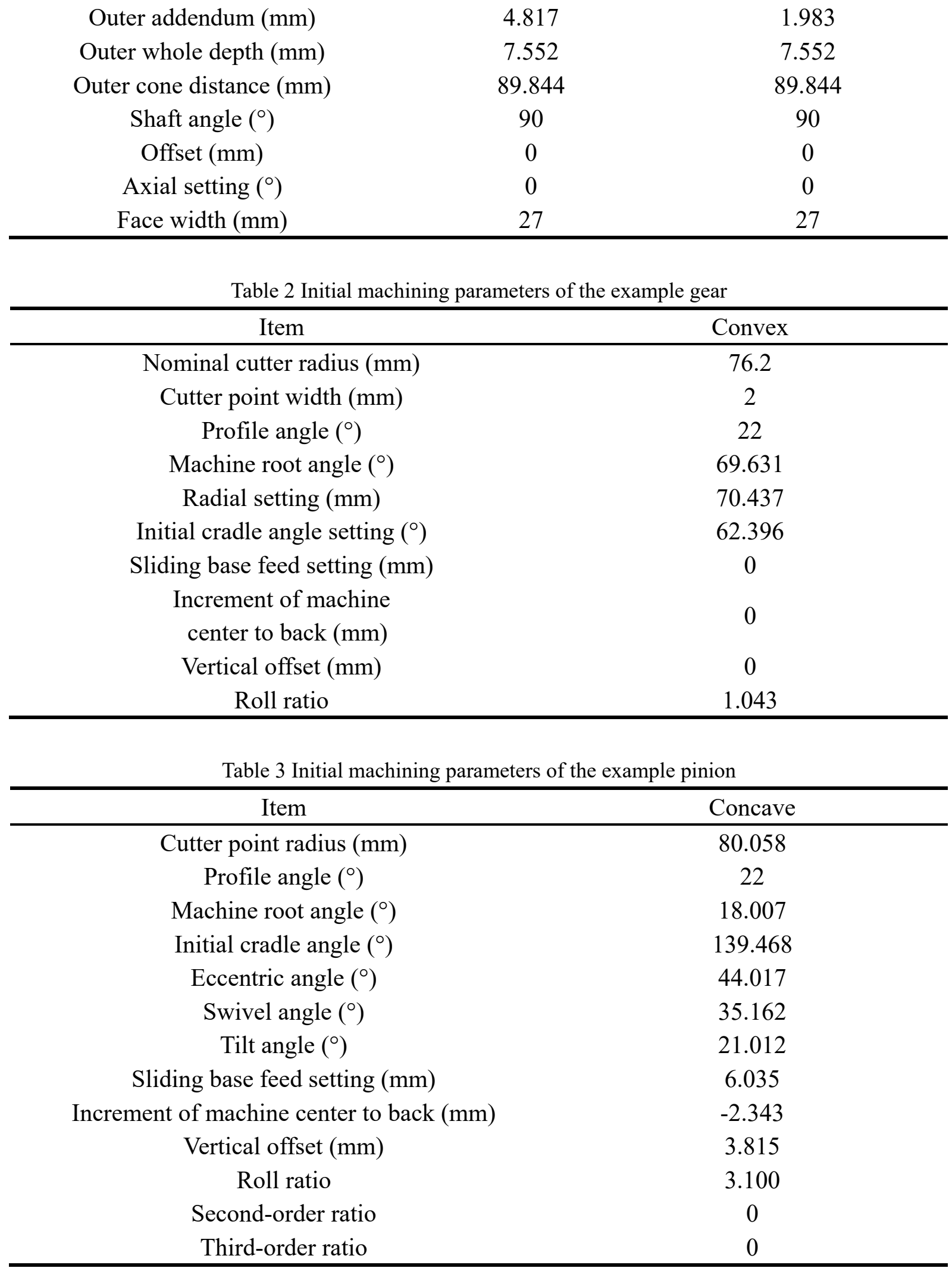

Substituting the parameters in Table 2 and Table 3 into Eqs. (12) and (13), respectively, generates the $3 \mathrm{D}$ model of the pinion machining tooth flank and its theoretical tooth flank by discretizing the tooth flank. The geometric topology deviations model of the initial pinion machining tooth flank and its theoretical tooth flank was established, as shown in Fig. 10. 


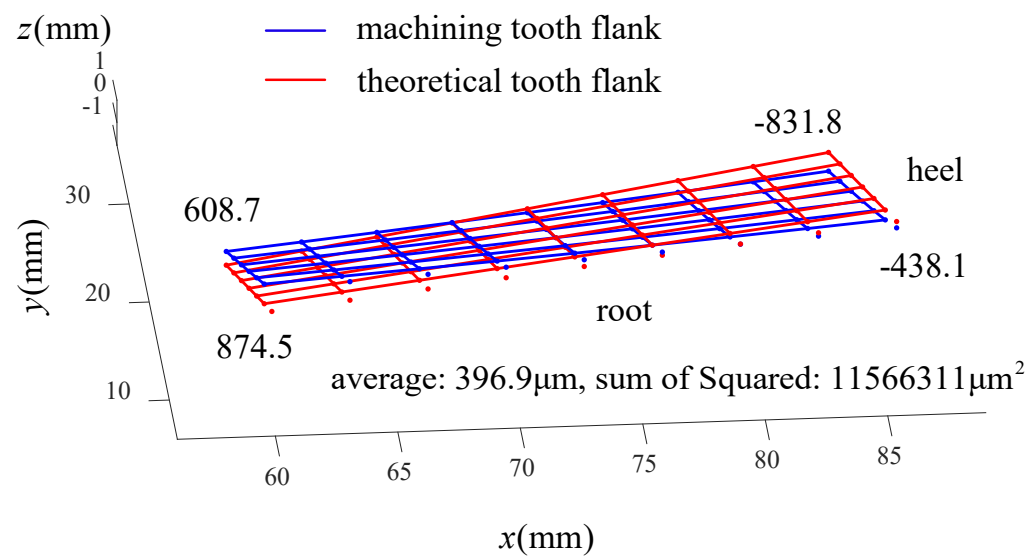

Fig. 10 Geometric topology deviations model of the initial pinion machining tooth flank and its theoretical tooth flank

Calculating the deviation value at each effective tooth flank point, the results in Fig. 10 show that the average value of the tooth flank deviations is $396.9 \mu \mathrm{m}$, the sum of squares is $11566311.1 \mu^{2}$, and the absolute value of the maximum is $874.5 \mu \mathrm{m}$. The data show that the deviation between the initial pinion machining tooth flank and its theoretical tooth flank is large, so it needs to be modified in advance based on some of the tooth flank machining parameters. The premodified machining parameters are listed in Table 4.

Table 4 Premodified machining parameters for the example pinion

\begin{tabular}{cc}
\hline Item & Concave \\
\hline Cutter point radius $(\mathrm{mm})$ & 80.058 \\
Profile angle $\left(^{\circ}\right)$ & 22 \\
Machine root angle $\left(^{\circ}\right)$ & 18.007 \\
Initial cradle angle $\left(^{\circ}\right)$ & 139.468 \\
Eccentric angle $\left(^{\circ}\right)$ & 44.017 \\
Swivel angle $\left(^{\circ}\right)$ & 35.162 \\
Tilt angle $\left(^{\circ}\right)$ & 21.012 \\
Sliding base feed setting $(\mathrm{mm})$ & 6.035 \\
Increment of machine center to back $(\mathrm{mm})$ & -2.343 \\
Vertical offset (mm) & 3.815 \\
Roll ratio & 3.100 \\
Second-order ratio & 0 \\
Third-order ratio & 0 \\
\hline
\end{tabular}

According to the machining parameters in Table 4, the geometric topology deviations model of the premodified pinion machining tooth flank and its theoretical tooth flank was established. As shown in Fig. 11, the average value of the tooth flank deviation is $18.1 \mu \mathrm{m}$, the sum of squares is $32131.5 \mu \mathrm{m}^{2}$, and the absolute value of the maximum is $101.7 \mu \mathrm{m}$. 


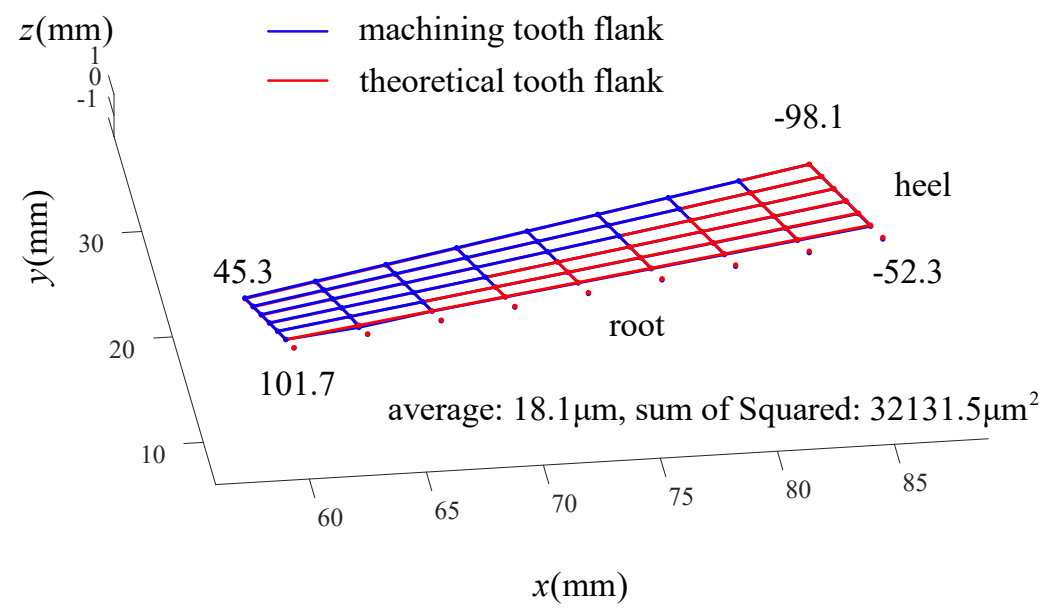

Fig. 11 Geometric topology deviations model of the premodified pinion machining tooth flank and its theoretical tooth flank.

The data show that through previous modification, the tooth flank deviations were effectively reduced on the premise of ensure no offset between the cutter head and the work pinion. Then, all the machining parameters of the pinion tooth flank were modified, and the modified machining parameters are listed in Table 5.

Table 5 Modified machining parameters for the example pinion

\begin{tabular}{cc}
\hline Item & Concave \\
\hline Cutter point radius $(\mathrm{mm})$ & 80.058 \\
Profile angle $\left(^{\circ}\right)$ & 22 \\
Machine root angle $\left(^{\circ}\right)$ & 18.007 \\
Initial cradle angle $\left(^{\circ}\right)$ & 139.468 \\
Eccentric angle $\left(^{\circ}\right)$ & 44.017 \\
Swivel angle $\left(^{\circ}\right)$ & 35.162 \\
Tilt angle $\left(^{\circ}\right)$ & 21.012 \\
Sliding base feed setting (mm) & 6.035 \\
Increment of machine & -2.343 \\
center to back (mm) & 3.815 \\
Vertical offset (mm) & 3.100 \\
Roll ratio & 0.145 \\
Second-order ratio & 0.001 \\
Third-order ratio &
\end{tabular}

Based on the parameters in Table 5, the geometric topology deviations model of the modified pinion machining tooth flank and its theoretical tooth flank was established. As Fig. 12 shows, the average value of the deviations is $0.6 \mu \mathrm{m}$, the sum of squares is $31.7 \mu \mathrm{m}^{2}$, and the absolute value of the maximum is $2.7 \mu \mathrm{m}$. 


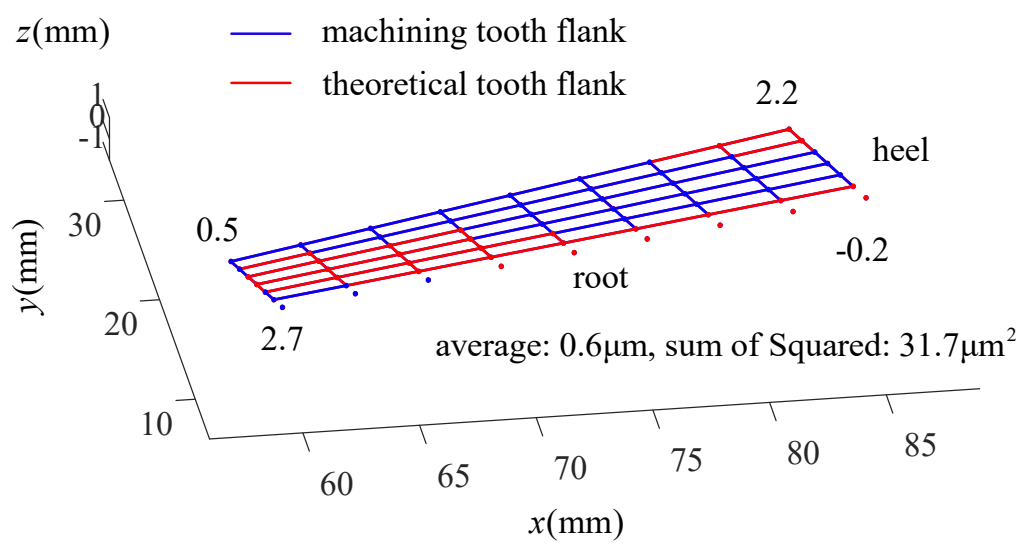

Fig. 12 Geometric topology deviations model of the modified pinion machining tooth flank and its theoretical tooth flank.

The results show that, based on the cutter head approximation machining method mentioned in this article, the pinion machining tooth flank can be effectively modified to the allowable deviations of its theoretical tooth flank by adjusting the cutting motions of the cutter head so that the pinion machining tooth flank can effectively approach its line contact theoretical tooth flank.

\subsection{Contact simulation analysis}

Contact simulation analysis was carried out on the example pair, and the main parameters of the finite element analysis model were set as follows: (1) the material properties of the gear and pinion are the same, with an elastic modulus of $2.06 \times 10^{5} \mathrm{Mpa}$, a Poisson's ratio of 0.3 , and a density of $7.85 \times 10^{-9} \mathrm{t} / \mathrm{mm}^{3}$. (2) The angular velocity of the pinion is $1 \mathrm{rad} / \mathrm{s}$, and the resistance torque applied to the gear is $10 \mathrm{~N} \cdot \mathrm{m}$. As shown in Fig. 13, the analysis results show that the gear and the pinion experience in line contact during instantaneous engagement.

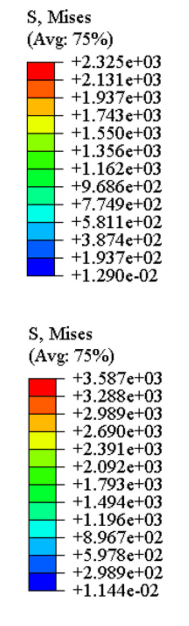

Step: Step-2
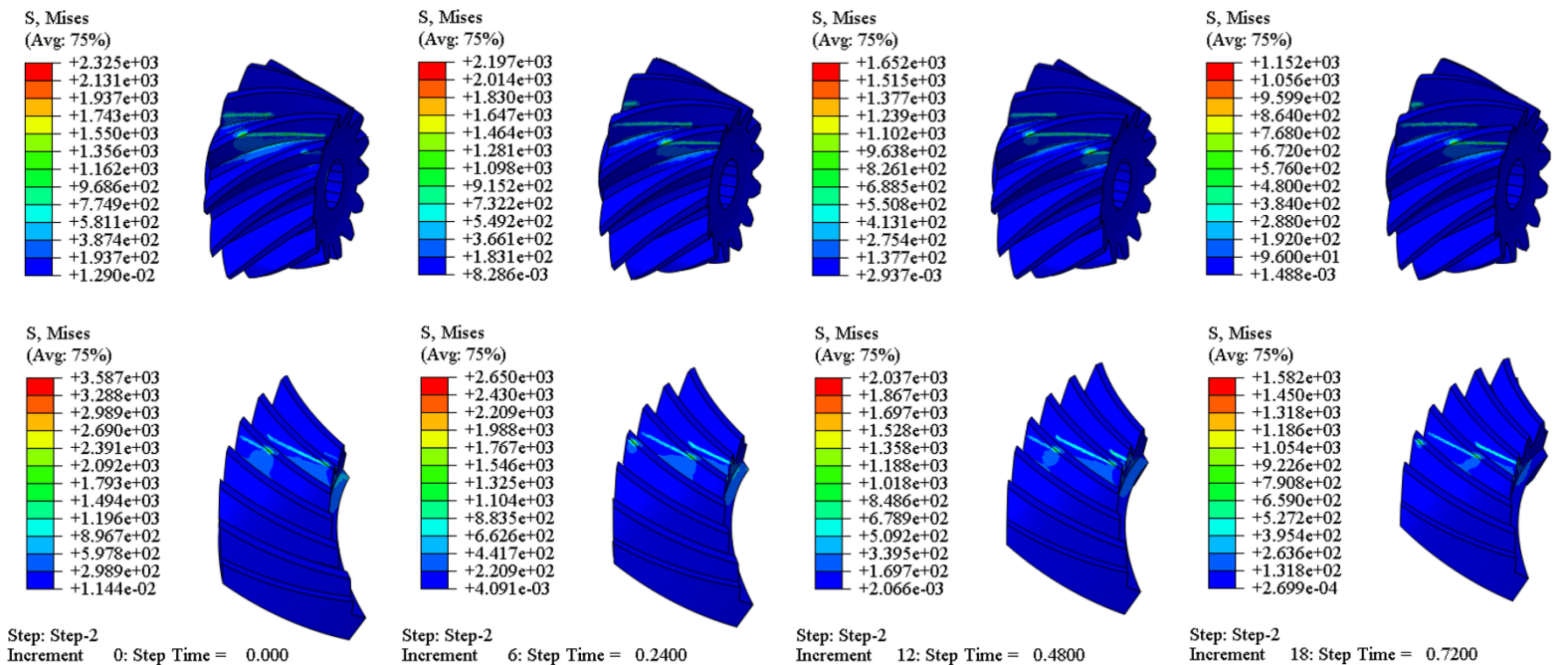

Step: Step-2 2 Step Time $=0.2400$

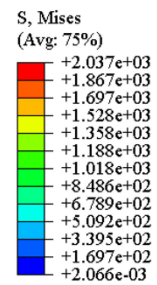

Step: Step-2
Increment 12: Step Time $=0.4800$

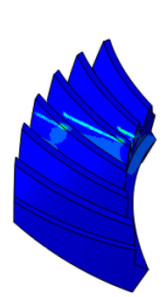

S, Mises
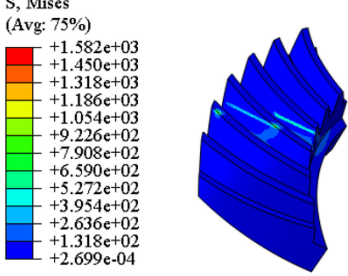

Step: Step-2
Increment $\quad$ 18: Step Time $=0.7200$

Fig. 13 Instantaneous contact line between pinion concave and gear convex

\subsection{Cutting and rolling tests}

To further verify the correctness of the tooth flank model and machining method, the cutting and rolling tests were carried out. Fig. 14 shows the cutting test processes of the pinion and gear based on a JCB32 five-axis CNC machine. Fig. 15 shows the actual contact area of 
the example pair obtained by an Y9550 bevel roll tester.

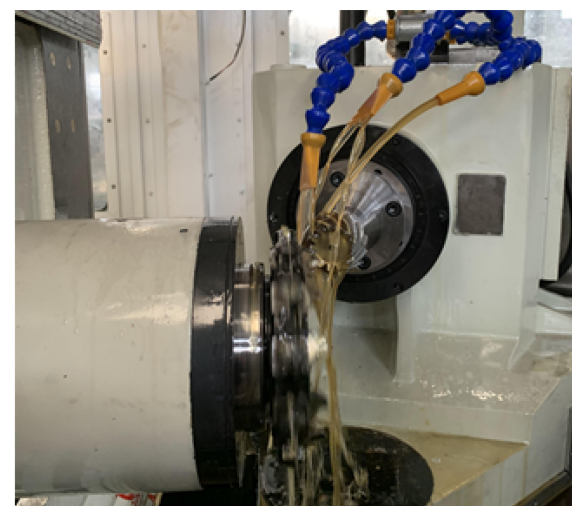

(a)

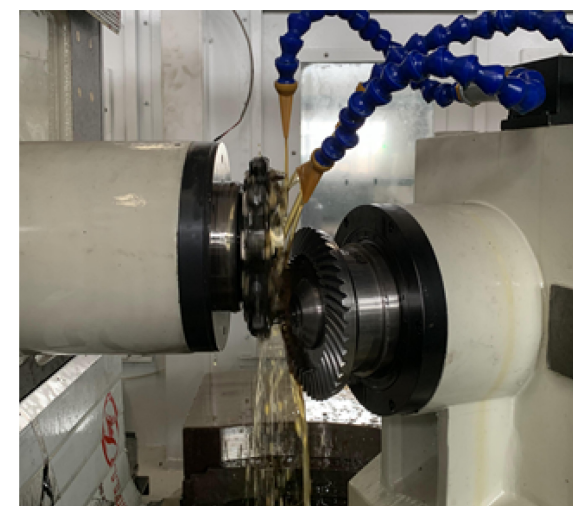

(b)

Fig. 14 Cutting test processes of the pinion and gear.

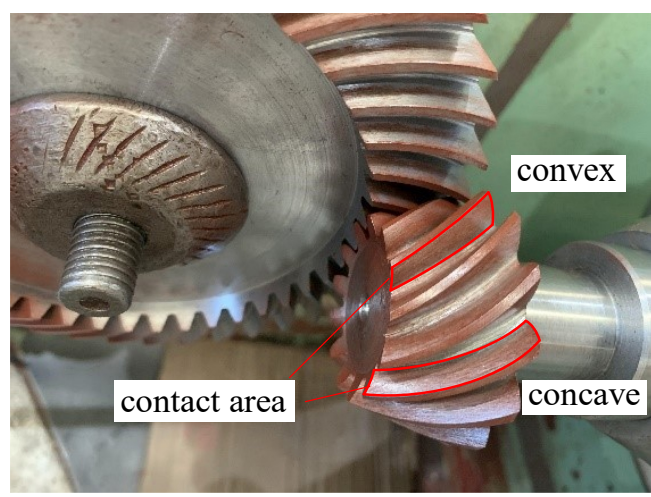

Fig. 15 Actual contact area of the example pair.

The result of the rolling test in Fig. 15 shows that the machined example pair is in fulltooth flank contact, which is consistent with the contact simulation result. The test results show that the cutter head approximation machining method based on controlling topological deviation can machine line contact spiral bevel gears under the conditions of existing machining equipment.

\section{Conclusion}

To solve the problem where line contact spiral bevel gear pairs cannot be directly machined by cutter heads, this paper proposed the cutter head milling approximation machining method of line contact spiral bevel gear pairs based on controlling tooth flank topology deviations. This method allows the tooth flanks machined by cutter heads to effectively approach the theoretical tooth flanks which can achieve line contact and realizes the line contact conjugate engagement of the spiral bevel gear pair processed based on the generating gear principle. The conclusions are as follows:

- Based on the mathematical model of line contact conjugate flanks, the gear tooth flank equation machined by the cutter head generating method and the theoretical tooth flank equation of the pinion conjugated to the gear were obtained. Then, based on the obtained pinion theoretical tooth flank and the pinion machining tooth flank machined by the tilting method, the geometric topological deviations model between the pinion machining tooth flank and its theoretical tooth flank was established, and an accurate 
comparison between the line contact theoretical tooth flank and the machining tooth flank was realized.

- Cutter head milling approximation machining method of line contact spiral bevel gear pairs based on controlling topology deviations was proposed. That is, with the pinion machining tooth flank approaching its theoretical tooth flank as the modification, by adjusting the cutting motions of the cutter head, the pinion machining tooth flank was modified to the allowable deviations range of its theoretical tooth flank so that the pinion machining tooth flank effectively approached its theoretical tooth flank, and the cutter head milling approximation machining of line contact spiral bevel gear pairs was realized.

- The contact simulation results show that the gear pair obtained by the cutter head milling approximation machining method is in line contact at the moment of engagement. The cutting and rolling tests obtained the gear pair with full-tooth flank contact. The test results show that the cutter head approximation machining method based on controlling topological deviations can machine line contact spiral bevel gears.

\section{Declarations:}

\section{Funding}

This work was supported by the National Natural Science Foundation of China (Grant numbers 51875395).

\section{Competing interests}

All authors certify that they have no affiliations with or involvement in any organization or entity with any financial interest or non-financial interest in the subject matter or materials discussed in this manuscript.

\section{Availability of data and material}

All data generated or analyzed during this study are included in this article.

\section{Authors' contributions}

All authors contributed to the study conception and design. Methodology, data analysis and validation were performed by Mingyang Wang. Resources and Supervision were performed by Yuehai Sun. The first draft of the manuscript was written by Mingyang Wang and all authors commented on previous versions of the manuscript. All authors read and approved the final manuscript.

\section{References}

1. Gleason Works.(1971) Method for designing hypoid blanks. Rochester, New York

2. Institute of Tianjin Gear Generator.(1989) Translation works of Gleason spiral bev el gear technical documentation. China Machine Press, Beijing

3 . Gleason Works.(1971) Calculation instructions generated spiral bevel gears duplex 
helical method. Rochester, New York

4. Litvin F L, Lee H T.(1989) Generation and tooth contact analysis of spiral bevel gears with predesigned parabolic functions of transmission error. NASA Lewis Re search Center, Chicago

5 . Litvin F L, Zhang Y.(1991) Local synthesis and tooth contact analysis of face-mil led spiral bevel gears. NASA Lewis Research Center, Chicago

6 . Litvin F L, Fuentes A.(2004) Gear Geometry and Applied Theory. Cambridge Uni versity Press, Cambridge

7 . Shih Y P (2010) A novel ease-off flank modification methodology for spiral bevel and hypoid gears. Mechanism and Machine Theory 45(8): 1108-1124. https://doi. org/10.1016/j.mechmachtheory.2010.03.010

8. Shih Y P, Sun Z H, Lai K L.(2017) A flank correction face-milling method for b evel gears using a five-axis CNC machine. International Journal of Advanced Ma nufacturing Technology, 91(9-12): 3635-3652. https://doi.org/10.1007/s00170-017-00 $\underline{32-8}$

9 . Artoni A, Gabiccini M, Guiggiani M.(2008) Nonlinear identification of machine s ettings for flank form modifications in hypoid gears. Journal of Mechanical Desig n, 130(11): 112602 https://doi.org/10.1115/1.2976454

10 . Artoni A, Bracci A, Gabiccini M, et al.(2009) Optimization of the loaded contact pattern in hypoid gears by automatic topology modification. Journal of Mechanical Design, 131(1): 011008 https://doi.org/10.1115/1.3013844

11. Gabiccini M, Artoni A, Guiggiani M.(2012) On the identification of machine setti ngs for gear surface topography corrections. Journal of Mechanical Design, 134(4): 041004 https://doi.org/10.1115/1.4006002

12 . Artoni A, Gabiccini M, Kolivand, M.(2013) Ease-off based compensation of tooth surface deviations for spiral bevel and hypoid gears: Only the pinion needs correc tions. Mechanism and Machine Theory, 61: 84-101 https://doi.org/10.1016/i.mechm achtheory.2012.10.005

13. Nie S W, Deng J, Deng X Z, et al.(2017) Tooth surface topology modification a nd processing parameters calculation for spiral bevel gears. Journal of Aerospace Power, 32(8): 2009-2016 https://doi.org/10.13224/j.cnki.jasp.2017.08.026

14 . Nie S W, Deng J, Deng X Z, et al.(2018) A flank modification method for spiral bevel gears based on mismatch topography adjustment. Journal of Advanced Mec hanical Design Systems and Manufacturing, 12(2) https://doi.org/10.1299/jamdsm.20 18 jamdsm0057

15 . Hong Z B.(2013) New milling method of spiral bevel gears based on generating principle of tooth surface with spherical involute. Dissertation, Jilin University

16. Alvarez A, Lacalle L N, Olaiz A, et al.(2015) Large spiral bevel gears on univer sal 5-axis milling machines: a complete process. Procedia Engineering, 132: 397-4 04 https://doi.org/10.1016/j.proeng.2015.12.511

17. Zhou Y S, Chen Z C, Tang J Y, et al.(2017) An innovative approach to NC pro gramming for accurate five-axis flank milling of spiral bevel or hypoid gears. Co mputer-Aided Design, 84: 15-24 https://doi.org/10.1016/j.cad.2016.11.003 
18 . Sue Y H, Li X H.(2017) Spread-Out helix modified roll of spiral bevel gears and tooth contact analysis. Journal of Tianjin University (Natural Science and Engine ering Technology Edition) 50(4): 421-428. https://doi.org/10.11784/tdxbz201605042

19. Xie S X.(2013) A genuine face milling cutter geometric model for spiral bevel a nd hypoid gears. International Journal of Advanced Manufacturing Technology 67 (9-12): 2619-2626. https://doi.org/10.1007/s00170-012-4678-y

20 . Garcia-Garcia R, Gonzalez-Palacios MA.(2018) Method for the geometric modelin $\mathrm{g}$ and rapid prototyping of involute bevel gears. International Journal of Advanced Manufacturing Technology 98(1-4): 645-656. https://doi.org/10.1007/s00170-018-22 $\underline{46-9}$

21. Mu Y M, Li W L, Fang Z D.(2019) Tooth surface modification method of facemilling spiral bevel gears with high contact ratio based on cutter blade profile co rrection. International Journal of Advanced Manufacturing Technology 106(7-8): 32 29-3237. https://doi.org/10.1007/s00170-019-04738-3

22. Mao S M, Guo B A, Li J G. China, 2010101243411, 2010-03-15

23 . Sue Y H, Yan D S. China, 2020106213596, 2020-06-30 